\title{
DETERMINAÇÃO DE AMÔNIA, NITRITO E NITRATO EM SOLO DE ÁREA OCUPADA POR ATERRO SANITÁRIO
}

\author{
DETERMINATION OF AMMONIA, NITRITE AND \\ NITRATE IN SOIL OF AREA OCCUPIED BY LANDFILL
}

\section{Pedro Daniel da Cunha Kemerich; Bruno Acosta Flores; Carlos Eduardo Balestrin Flores; Rafael Borth da Silveira; Jacson Rodrigues França; Willian Fernando de Borba; Ademir Eloi Gerhardt; Guilherme Barros}

\author{
Universidade Federal de Santa Maria, Santa Maria, RS, Brasil. E-mail \\ rosktiao@hotmail.com, carlos.ebf@hotmail.com; rfl-b-s@ hotmail.com; \\ jacson.ambiental@homail.com; borba_willian@hotmail.com; \\ adegerhardt@bol.com.br; guilherme_barrosp@hotmail.com
}

\begin{abstract}
RESUMO
Com o aumento da população mundial e da industrialização, surge, cada vez mais, a necessidade de se dar destino correto aos resíduos produzidos pelo ser humano. Os aterros sanitários fazem um contraponto à antiga forma de disposição dos resíduos sólidos, conhecidos como lixões. As legislações atuais buscam, cada vez mais, realizar a gestão dos resíduos, visando à conservação do meio ambiente. Com base nisso, o presente estudo tem por objetivo analisar as variações encontradas nas concentrações dos compostos nitrogenados nitrito $\left(\mathrm{NO}_{2}{ }^{-}\right)$, nitrato $\left(\mathrm{NO}_{3}{ }^{-}\right)$e amônia $\left(\mathrm{NH}_{3}{ }^{-}\right)$, em solo de área ocupada por aterro sanitário. As amostras de solo foram coletadas através de tradagem manual em 10 pontos de amostragem, nas profundidades de 0 a $300 \mathrm{~cm}$. $\mathrm{O}$ nitrito apresentou concentração média de $0,004 \pm 0,004 \mathrm{mg} \mathrm{g}^{-1}$, para o nitrato a média foi de $0,129 \pm 0,074$ $\mathrm{mg} \mathrm{g}^{-1}$ e para amônia a média foi de $0,217 \pm 0,142 \mathrm{mg} \mathrm{g}^{-1}$. Pela análise estatística obteve-se correlação inversa entre os parâmetros profundidade e amônia, o mesmo ocorreu entre amônia com nitrito e nitratos. Os resultados mostram que nem sempre as maiores concentrações dos compostos nitrogenados se encontram em pontos de maior recepção das águas oriundas do escoamento superficial, sendo que apenas para nitrato, a maior concentração foi encontrada em uma das cotas mais baixas do terreno.
\end{abstract}

Palavras-chave: Contaminação. Compostos nitrogenados. Resíduos sólidos.

\footnotetext{
ABSTRACT

The increasing world population and industrialization impose the need to properly dispose of waste produced by humans. Landfills are a counterpoint to the ancient form of disposal of solid waste, known as dumps. Current laws perform waste management, aimed at conserving the environment. Having this basis, the present study aims to analyze the variations found in the concentrations of nitrite nitrogen $\left(\mathrm{NO}_{2}{ }^{-}\right)$, nitrate $\left(\mathrm{NO}_{3}{ }^{-}\right)$and ammonia $\left(\mathrm{NH}_{3}{ }^{-}\right)$, ground area occupied by landfill. Soil
} 
samples were collected from borehole manual in 10 sampling points, depths $0-300 \mathrm{~cm}$. The nitrite concentration showed average $0,004 \pm 0,004 \mathrm{mg} \mathrm{g}^{-1}$ for nitrate, the average was $0,129 \pm 0,074 \mathrm{mg} \mathrm{g}^{-}$ ${ }^{1}$ for ammonia and the average was $0,217 \pm 0,142 \mathrm{mg} \mathrm{g}^{-1}$. The statistical analysis was obtained inverse correlation between the parameters depth and ammonia, the same occurred between ammonia nitrite and nitrate. The results show that not always the higher concentrations of nitrogen compounds are at most points receive water coming from the runoff, with only nitrate, the highest concentration found in one of the lower levels of the ground.

Keywords: Contamination. Nitrogen. Solid Waste.

\section{INTRODUÇÃO}

Em função do crescente processo de industrialização e do acelerado crescimento populacional, a geração per capta de resíduos sólidos urbanos implica num imenso volume de lixo, gerado diariamente, que precisa ser gerenciado (COSTA et al., 2002).

A possibilidade de contaminação ambiental, associada à necessidade de grandes áreas para a disposição e tratamento, tornou a solução do problema do lixo urbano, um dos mais sérios desafios para as administrações públicas (SANTANA e ENCINAS, 2009).

O problema do gerenciamento dos resíduos sólidos na sociedade atual tornou-se complexo devido à quantidade e diversidade dos resíduos. Destaca-se ainda a explosão das áreas urbanas, a limitação dos recursos financeiros públicos em muitas cidades, os impactos da tecnologia e as limitações tanto de energia quanto de recursos naturais (ALMEIDA, 2009).

Alternativas como a incineração ou usinas de compostagem não descartam a utilização de aterros de resíduos, como aterros de cinzas e para os materiais inadequados para o aproveitamento nesse processo (COSTA et al., 2002).

A técnica de deposição de resíduos em aterros sanitários se caracteriza por ser um processo planejado com redução de impactos já que os resíduos são confinados no solo através do emprego de normas específicas de engenharia com a finalidade de preservar o meio ambiente e a saúde pública. As áreas de aterro sanitário devem estar localizadas em local devidamente projetado e adaptado de forma a receber os resíduos de modo compatível com a Legislação Ambiental (MEINERZ et al., 2009).

O aterro sanitário se faz alternativa ao modelo de disposição utilizado durante muito tempo, conhecido como lixão, onde os resíduos são lançados no solo, sem nenhuma impermeabilização, propiciando a contaminação do solo e das águas subterrâneas. Outra diferença observada, é que no aterro sanitário, diariamente, a camada de lixo depositada é coberta por uma camada de solo, assim evitando o contado do lixo com possíveis vetores de transmissão de doenças, como gatos, cachorros, urubus e outros animais.

Porém, um dos grandes problemas encontrados no gerenciamento de aterros sanitários de resíduos urbanos diz respeito à produção e ao tratamento do lixiviado produzido. Isso ocorre especialmente nos casos em que o aterro sanitário está situado em áreas com alta pluviosidade, onde a produção de lixiviado é abundante e, consequentemente, o risco de contaminação do solo, de lençóis freáticos e de leitos de rios é relativamente alto, podendo gerar forte impacto ambiental (MOURA, 2008).

Aumento significativo de nutrientes (nitrogênio, alumínio, cálcio e potássio) no solo e em águas subterrâneas, foi observado por Santana e Encinas (2004), principalmente em regiões bem próximas aos depósitos de lixo.

Sendo assim, o presente estudo tem por objetivo analisar as variações encontradas nas concentrações de amônia $\left(\mathrm{NH}_{3}{ }^{-}\right)$, nitrato $\left(\mathrm{NO}_{3}{ }^{-}\right)$e nitrito $\left(\mathrm{NO}_{2}{ }^{-}\right)$em solo de área ocupada por aterro sanitário. 


\section{MATERIAIS E MÉTODOS}

\subsection{Caracterização da área de estudo}

O município de Seberi está situado no noroeste do estado do Rio Grande do Sul, Brasil, latitude $27^{\circ} 28^{\prime} 4^{\prime \prime} \mathrm{S}$, longitude $53^{\circ} 24^{\prime} 09^{\prime \prime}$ e altitude de $546 \mathrm{~m}$ do nível do mar. Abrange área de 301 $\mathrm{km}^{2}$ e conta com população de 11098 habitantes, pertencendo à bacia hidrográfica do Rio Uruguai com clima subtropical úmido (IBGE, 2009). O Consórcio Intermunicipal de Gestão de Resíduos Sólidos (CIGRES) está localizado na BR $386 \mathrm{~km} \mathrm{43,} \mathrm{Distrito} \mathrm{de} \mathrm{Osvaldo} \mathrm{Cruz} \mathrm{pertencente} \mathrm{à} \mathrm{cidade}$ de Seberi - RS. É um consórcio entre 30 municípios com área total de 7,77 ha e abrangência de $488360 \mathrm{~km}^{2}$, atendendo cerca de 162 mil habitantes, recebendo aproximadamente 1200 toneladas de resíduos sólidos urbanos mensalmente.

\subsection{Localização dos pontos de amostragem e coleta de amostras}

A metodologia usada para escolha dos pontos de amostragem (Figura 1) e coleta de amostras foi a mesma utilizada por Kemerich et al. (2012), onde as tradagens para coleta das amostras foi realizada em função da topografia existente no terreno e do fluxo preferencial de água superficial, determinado com o auxílio do software Surfer 10 (GOLDEN SOFTWARE, 2004) utilizando-se o método de interpolação matemática Krigagem (LANDIN e SATURATO, 2002). Foram considerados 10 pontos de coleta, sendo que estes receberam nomenclatura variando de P1 a P10, sendo P1 o ponto de maior cota topográfica $(548 \mathrm{~m})$ e P10 o de menor $(518 \mathrm{~m})$.

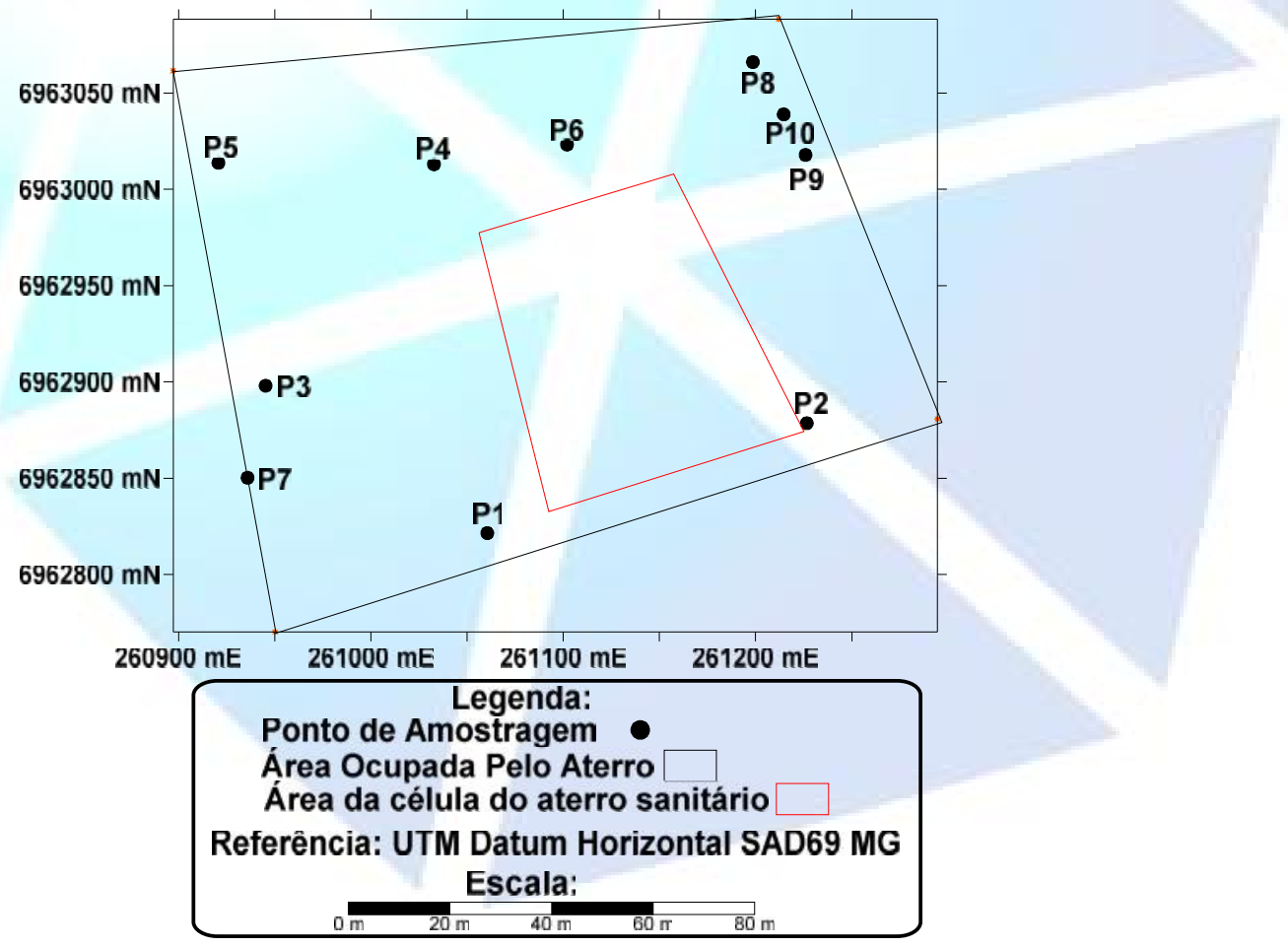

Figura 1. Área de estudo no município de Seberi - RS.

Para a coleta das amostras foi utilizado o trado manual Sonda Terra de $3 \mathrm{~m}$ de comprimento (Figura 2a). Cada amostra coletada foi armazenada em sacos de plástico e recebeu identificação correspondendo à localização do ponto de amostragem e a profundidade da coleta. Para evitar alterações nos resultados o trado passou por lavagem com água destilada a cada nova coleta (Figura 2b). Para este estudo foram utilizadas amostras coletadas nas profundidades de 0 a $300 \mathrm{~cm}$, sendo avaliado o total de 70 amostras, para os parâmetros de $\mathrm{NH}_{3}{ }^{-}, \mathrm{NO}_{3}{ }^{-}$e $\mathrm{NO}_{2}{ }^{-}$. 


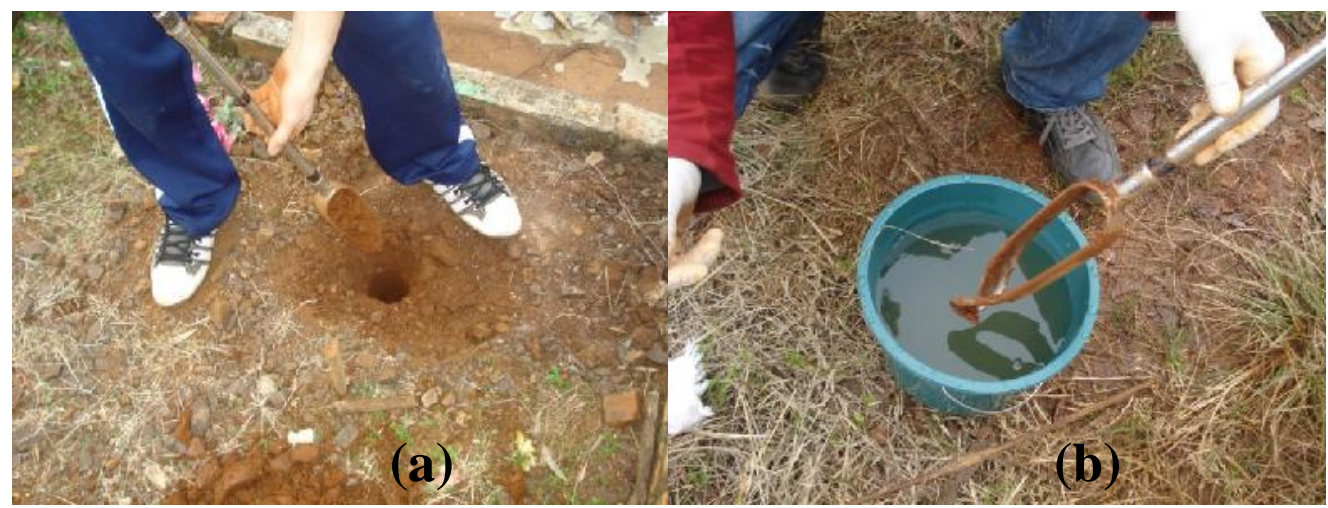

Figura 2. Tradagem efetuada no local de estudo, utilizando trado manual Sonda terra $3 \mathrm{~m}$ (a) e limpeza do trado em água destilada (b), Seberi - RS, 2012.

\subsection{Preparo de amostras e determinação de compostos nitrogenados}

As determinações de $\mathrm{NH}_{3}{ }^{-}, \mathrm{NO}_{3}{ }^{-}$e $\mathrm{NO}_{2}{ }^{-}$foram realizadas segundo metodologia descrita por Tedesco et al. (1985), usando os seguintes equipamentos: a) $\mathrm{NH}_{3}{ }^{-}$e $\mathrm{NO}_{3}{ }^{-}$: destilador de nitrogênio MA-036/MARCONI; b) $\mathrm{NO}_{2}^{-}$: espectrofotometro Nova 2100 UV. O destilador de nitrogênio usado para a determinação de $\mathrm{NH}_{3}{ }^{-}$e $\mathrm{NO}_{3}{ }^{-}$tem como limite de detecção (L. D.) $0,00035 \mathrm{mg} \mathrm{g}^{-1}$. Para $\mathrm{NO}_{2}{ }^{-}$ o L. D. é de $0,00000202 \mathrm{mg} \mathrm{g}^{-1}$.

\subsection{Espacialização dos resultados obtidos e correlação estatística}

Para a espacialização das informações obtidas nas análises de solo, utilizou-se o programa Surfer 10 da Golden Software. Como método de elaboração matemática foi utilizada a Krigagem (LANDIM e STURATO, 2002). Inicialmente, foram lançados os valores para ponto de amostragem de solo (com o parâmetro a ser espacializado) com as coordenadas Universal Transversa de Mercator (UTM) escolhendo-se a opção Contour Map e gerando-se um cartograma de contorno da superfície da área estudada. Logo após, foram espacializadas as informações de interesse com o uso da opção Post Map. Para a realização da correlação estatística foi utilizado o Software Statistica 7 (KEMERICH et al., 2012).

\section{RESULTADOS E DISCUSSÃO}

A Figura 3 mostra o comportamento dos parâmetros analisados (amônia, nitrito e nitrato) em todos os pontos de amostragem (P1 a P10).

\subsection{Amônia $\left(\mathrm{NH}_{3}{ }^{-}\right)$}

A Figura 4 ilustra a variação da concentração de $\mathrm{NH}_{3}{ }^{-}$nas profundidades de 0 (a), 50 (b), 100 (c) e $150 \mathrm{~cm}$ (d). A maior concentração $\left(0,752 \mathrm{mg} \mathrm{g}^{-1}\right.$ de solo) foi observada no P8 a $150 \mathrm{~cm} \mathrm{e} \mathrm{a}$ menor $\left(0,080 \mathrm{mg} \mathrm{g}^{-1}\right.$ de solo) foi obtida no P9 a $50 \mathrm{~cm}$. Na profundidade de $0 \mathrm{~cm}$, o maior valor esteve presente no P6 na concentração de $0,297 \mathrm{mg} \mathrm{g}^{-1}$ de solo, e o menor foi observado no P7 na concentração de $0,084 \mathrm{mg} \mathrm{g}^{-1}$ de solo. A $50 \mathrm{~cm}$ de profundidade, o maior valor foi encontrado no P6 $\left(0,385 \mathrm{mg} \mathrm{g}^{-1}\right.$ de solo) e o menor no P9 (0,080 $\mathrm{mg} \mathrm{g}^{-1}$ de solo).

A $100 \mathrm{~cm}$, a maior concentração observada foi de $0,612 \mathrm{mg} \mathrm{g}^{-1}$ de solo (P8), e a menor foi de $0,087 \mathrm{mg} \mathrm{g}^{-1}$ de solo (P9). Na profundidade de $150 \mathrm{~cm}$, o P8 apresentou a maior concentração (0,752 $\mathrm{mg} \mathrm{g}^{-1}$ de solo), e a menor foi observada no P2 $\left(0,140 \mathrm{mg} \mathrm{g}^{-1}\right.$ de solo). Para uma média de todas as análises, este elemento apresentou concentração de $0,217 \pm 0,142 \mathrm{mg} \cdot \mathrm{g}^{-1}$. 


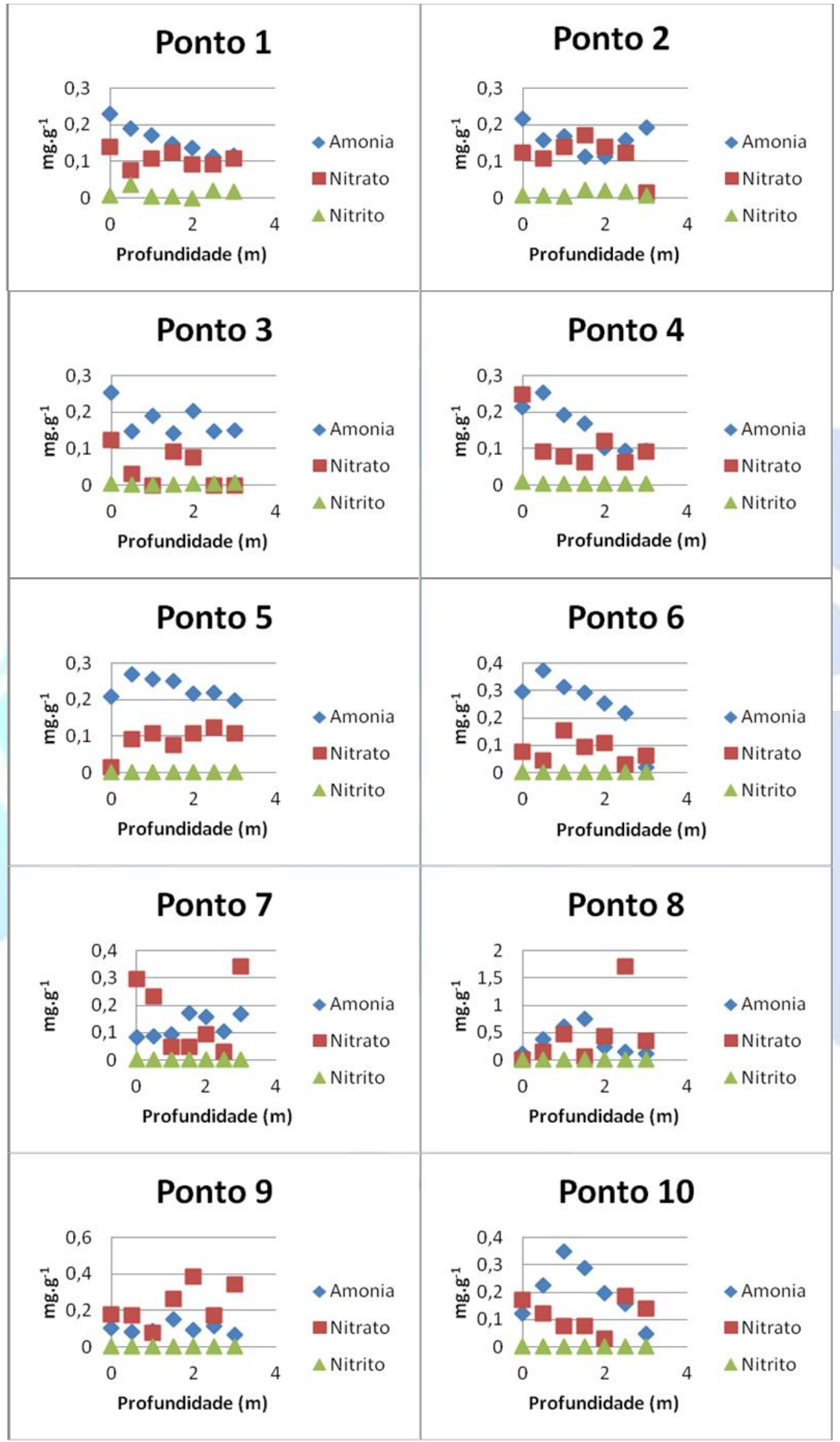

Figura 3. Variação da concentração dos parâmetros analisados na área de estudo, Seberi-RS, 2013. 


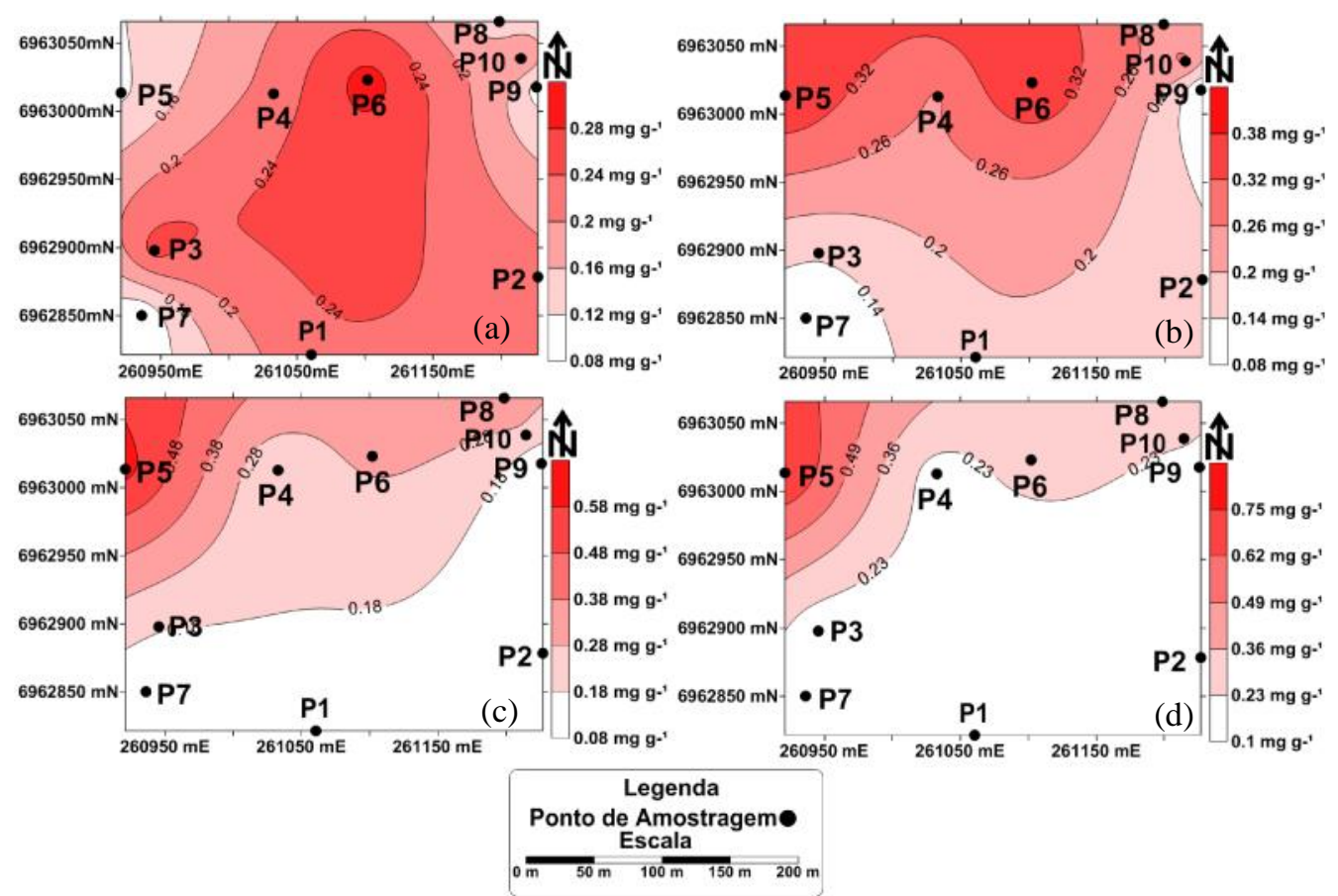

Figura 4. Concentração de amônia nas profundidades de 0 (a), 50 (b),100 (c) e 150 cm (d) na área de estudo.

A Figura 5 ilustra a variação da concentração de $\mathrm{NH}_{3}{ }^{-}$nas profundidades de 200 (a), 250 (b) e $300 \mathrm{~cm}$ (c), onde a maior concentração foi observada no P6 $\left(0,252 \mathrm{mg} \mathrm{g}^{-1}\right.$ de solo) a $200 \mathrm{~cm}$, e a menor foi encontrada no P9 $\left(0,066 \mathrm{mg} \mathrm{g}^{-1}\right.$ de solo) a $300 \mathrm{~cm}$. Na profundidade de $200 \mathrm{~cm}$, o maior valor esteve presente no P6 $\left(0,252 \mathrm{mg} \mathrm{g}^{-1}\right.$ de solo), e o menor foi encontrado no P9 $\left(0,091 \mathrm{mg} \mathrm{g}^{-1} \mathrm{de}\right.$ solo). Na profundidade de $250 \mathrm{~cm}$, o maior valor foi obtido no P5 $\left(0,220 \mathrm{mg} \mathrm{g}^{-1}\right.$ de solo) e o menor no P4 (0,094 $\mathrm{mg} \mathrm{g}^{-1}$ de solo). A $300 \mathrm{~cm}$, o P5 apresentou a maior concentração $\left(0,199 \mathrm{mg} \mathrm{g}^{-1} \mathrm{de}\right.$ solo), e a menor foi observada no P9 (0,066 $\mathrm{mg} \mathrm{g}^{-1}$ de solo).

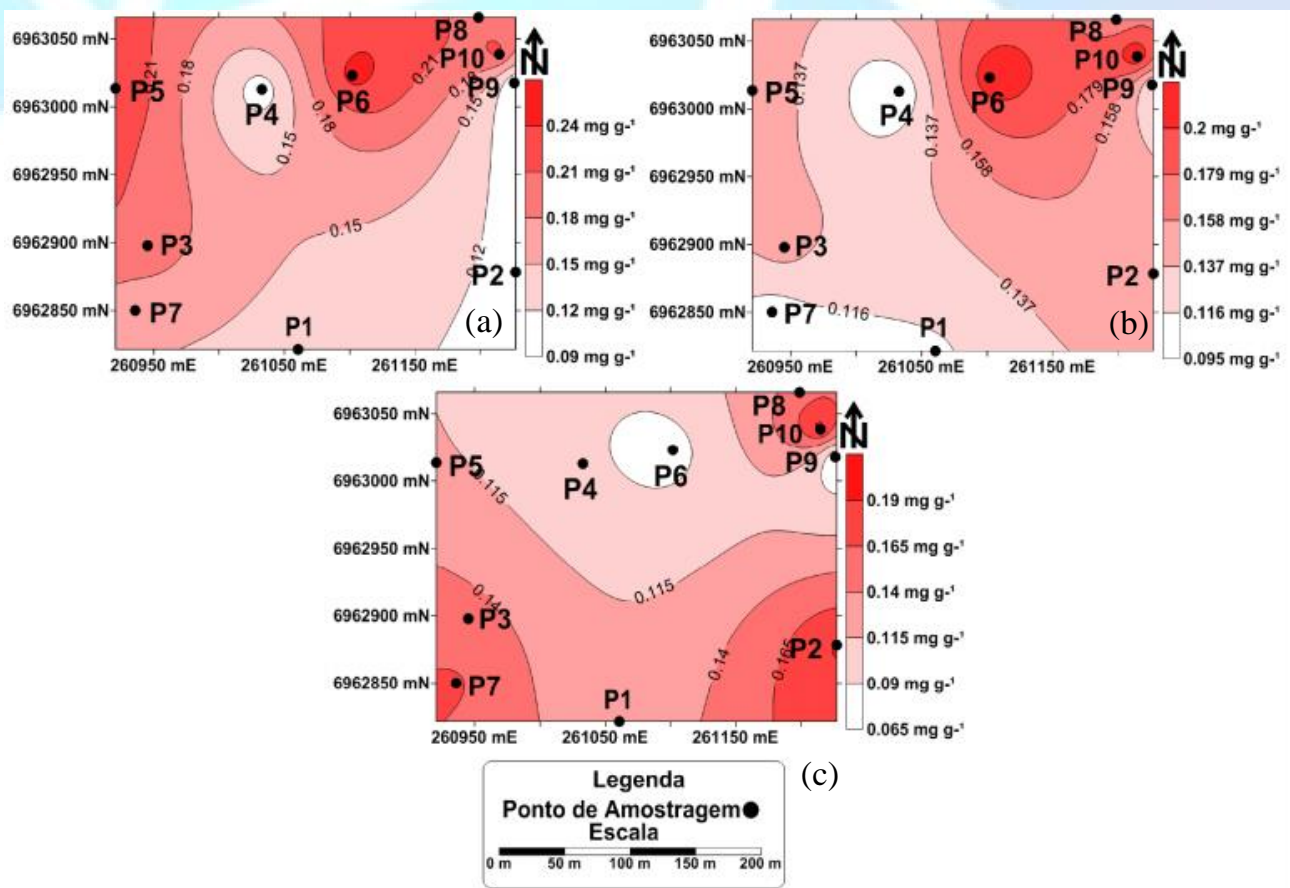

Figura 5. Concentração de amônia nas profundidades de 200 (a), 250 (b) e 300 cm (c), na área de estudo. 
A amônia apresentou concentrações mais elevadas que os demais elementos analisados em $80 \%$ dos pontos de amostragem. Com isso, apresentou valores inferiores que nitrato no ponto 9 em todas as profundidades e em algumas profundidades distintas nos demais pontos, com ênfase no ponto 7 que apresentou valores maiores para nitrato na amostra superficial e nas profundidade de 0,5 e $3 \mathrm{~m}$. Em relação a suas concentrações, ocorreram variações entre $\left(0,119\right.$ à $\left.0,375 \mathrm{mg} \mathrm{g}^{-1}\right)$. Vários fatores podem ter influenciado nisso, como por exemplo a textura do solo (teor de argila), irregularidade do terreno e a alta carga de matéria orgânica e compostos tóxicos que não são distribuídos de forma linear. Em $60 \%$ dos casos, a concentração de amônia diminui de acordo com sua profundidade, apresentando concentrações maiores nas amostras superficiais e menores em coletas mais profundas. No ponto 9 os valores não tiveram mudanças significativas entre as profundidades, variando de 0,066 à $0,151 \mathrm{mg} \mathrm{g}^{-1}$. O ponto 10 apresentou a maior concentração $\left(0,350 \mathrm{mg} \cdot \mathrm{g}^{-1}\right)$ na amostra coletada a $1 \mathrm{~m}$ da superfície. Nos pontos 7 e 8 a concentração alterou de forma semelhante, onde a mesma foi aumentando da coleta superficial até a 1,5 m de profundidade e diminuindo de 1,5 a $3 \mathrm{~m}$ de profundidade. Desta forma pode se afirmar que a amônia tende a ter maior concentração na parte mais superficial, devido o grande grau de argila no solo, o que contribui diretamente na taxa de infiltração interferindo na concentração de compostos.

Segundo Campos et al. (2010) o $\mathrm{NH}_{3}{ }^{-}$é uma molécula polar, devido ao arranjo assimétrico dos seus átomos, na forma de uma pirâmide trigonal. Isto provoca acúmulo de cargas elétricas junto ao átomo de nitrogênio, o que torna negativa esta extremidade da molécula. $\mathrm{O}$ caráter polar é a razão para sua grande solubilidade em água. Dissolvida na água, a $\mathrm{NH}_{3}{ }^{-}$pode se ionizar, recebendo um íon hidrogênio e se convertendo no íon amônio $\left(\mathrm{NH}_{4}{ }^{+}\right)$. Por ter carga, o íon $\mathrm{NH}_{4}{ }^{+}$contribui para a condutividade do meio onde se encontra.

Pelo conhecimento do ciclo do nitrogênio pode-se afirmar que a $\mathrm{NH}_{3}{ }^{-}$é produto das primeiras fases da decomposição anaeróbia. É gerada pela própria decomposição da matéria orgânica. As proteínas da fração orgânica do lixo aterrado são convertidas em grande parte em amônia pela ação de bactérias heterotróficas em condições anaeróbias ou aeróbias (Melo, 2003). Em seguida surgem os nitritos e, não havendo interrupção do processo, formam-se produtos mais estáveis, os nitratos (COSTA, 1999).

Como citam He et al. (2007) o tratamento de lixiviado é uma etapa de grande importância no sistema de gerenciamento de resíduos sólidos devido ao elevado teor de amônia $\left(\mathrm{NH}_{4}-\mathrm{N}\right)$.

A amônia pode ser encontrada na forma livre $\mathrm{NH}_{3}{ }^{-}$ou ionizada na forma $\mathrm{NH}_{4}{ }^{+}$, dependendo do $\mathrm{pH}$ do meio (Rodrigues, 2007). Em concentrações altas contribuem para o aumento de toxicidade dos efluentes, afetando peixes e inibindo o metabolismo de microrganismos.

Tendo em vista Martinez (2007) retrata que para seres humanos, em particular, a exposição à concentração muito alta de amônia gasosa pode causar danos sérios nos pulmões ou ser letal.

\subsection{Nitrato $\left(\mathrm{NO}_{3}{ }^{-}\right)$}

O nitrato é um sal bastante solúvel, característico da contaminação antiga por matéria orgânica, presente em grande quantidade em lixiviados de aterros sanitários (COSTA, 2002). Por ser um ânion, não é retido pelos 66 colóides argilosos ou orgânicos do solo, negativamente carregados, o que permite a avaliação do avanço da solução contaminada através do meio poroso (MARIOTTI, 1998).

Os nitratos resultam da degradação microbiana de substâncias orgânicas nitrogenadas, como proteínas, e íons $\mathrm{NH}_{3}{ }^{-}$, as quais são biologicamente oxidadas para nitritos e nitratos num processo realizado em duas etapas (Araújo et al., 2005)

A Figura 6 ilustra a variação da concentração de $\mathrm{NO}_{3}{ }^{-}$nas profundidades de 0 (a), 50 (b), 100 (c) e $150 \mathrm{~cm}(\mathrm{~d})$, onde a maior concentração $\left(0,465 \mathrm{mg} \mathrm{g}^{-1}\right.$ de solo) foi observada no P8 a 100 $\mathrm{cm}$, e a menor (<L.D.) foi observada no P3 a $100 \mathrm{~cm}$. Na profundidade de $0 \mathrm{~cm}$, o maior valor esteve presente no P7 na concentração de $0,294 \mathrm{mg} \mathrm{g}^{-1}$ de solo, e a menor foi observada no P8 na 
concentração de a $0,015 \mathrm{mg} \mathrm{g}^{-1}$ de solo. Na profundidade de $50 \mathrm{~cm}$, o maior valor foi obtido no P7 $\left(0,232 \mathrm{mg} \mathrm{g}^{-1}\right.$ de solo) e o menor no P3 $\left(0,031 \mathrm{mg} \mathrm{g}^{-1}\right.$ de solo). A $100 \mathrm{~cm}$ de profundidade, a maior concentração observada foi de $0,465 \mathrm{mg} \mathrm{g}^{-1}$ de solo (P8), e a menor (<L.D.) foi encontrada no P3. Na profundidade de $150 \mathrm{~cm}$, o P9 apresentou a maior concentração $\left(0,263 \mathrm{mg} \mathrm{g}^{-1}\right.$ de solo), e a menor foi observada no P7 $\left(0,046 \mathrm{mg} \mathrm{g}^{-1}\right.$ de solo). Para uma média de todas as análises, este elemento apresentou concentração de $0,129 \pm 0,074 \mathrm{mg} \cdot \mathrm{g}^{-1}$.

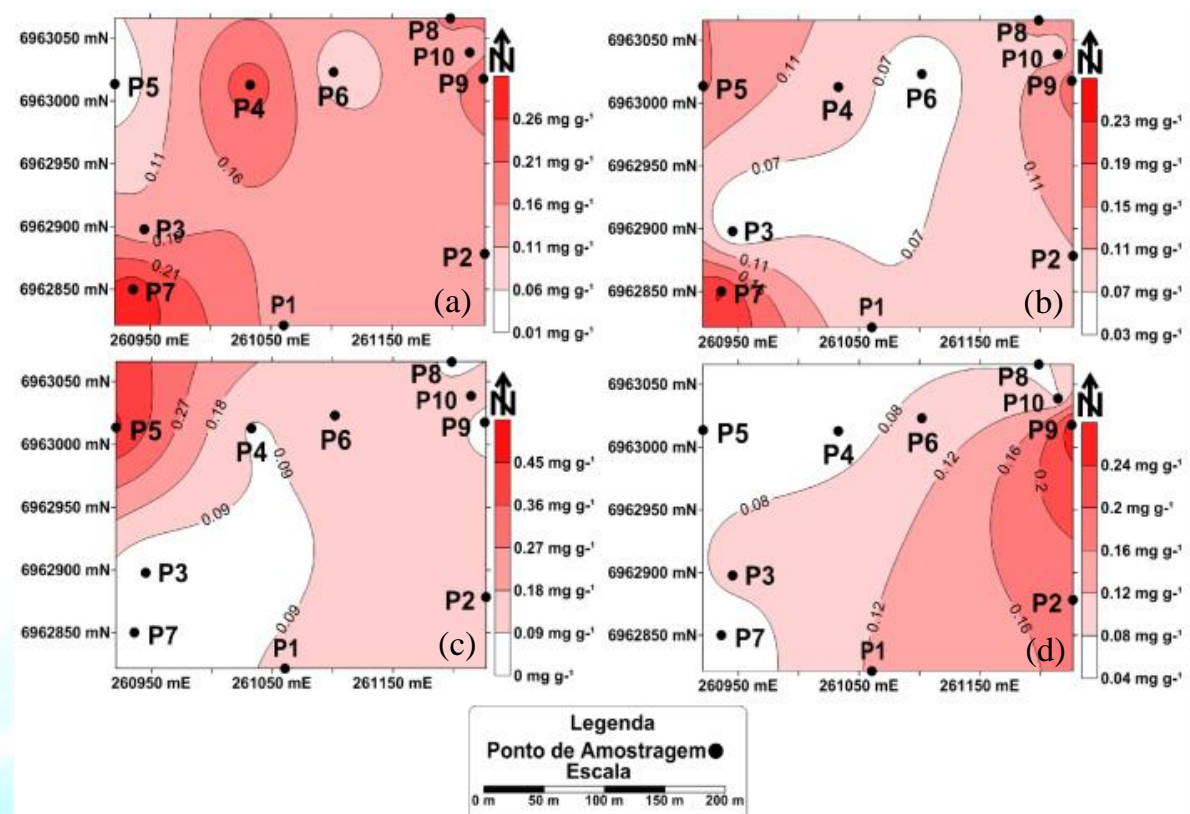

Figura 6. Concentração de nitrato nas profundidades de 0 (a), 50 (b), 100 (c) e 150 cm (d), na área de estudo.

A Figura 7 ilustra a variação da concentração de $\mathrm{NO}_{3}{ }^{-}$nas profundidades de 200 (a), 250 (b) e $300 \mathrm{~cm}$ (c), onde a maior concentração foi observada no P8 $\left(1,705 \mathrm{mg} \mathrm{g}^{-1}\right.$ de solo) a $250 \mathrm{~cm}$, e a menor foi observada no P3 (<L.D.) a $300 \mathrm{~cm}$. Na profundidade de $200 \mathrm{~cm}$, o maior valor este presente no P8 (0,434 $\mathrm{mg} \mathrm{g}^{-1}$ de solo), enquanto o menor valor foi encontrado no P10 $\left(0,031 \mathrm{mg} \mathrm{g}^{-1}\right.$ de solo). Na profundidade de $250 \mathrm{~cm}$, o maior valor foi obtido no P8 (1,705 mg g ${ }^{-1}$ de solo) e o menor no P3 (<L.D). A $300 \mathrm{~cm}$ de profundidade o P9 apresentou a maior concentração $(0,341 \mathrm{mg}$ $\mathrm{g}^{-1}$ de solo), e a menor foi observada no P3 (<L.D).

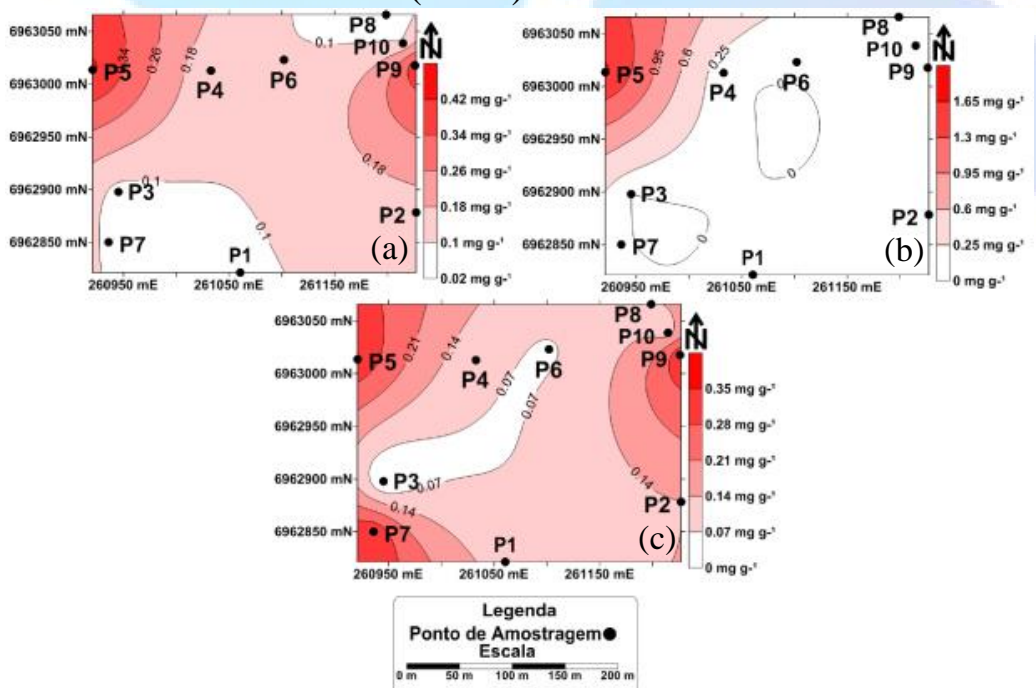

Figura 7. Concentração de nitrato (em) nas profundidades de 200 (a), 250 (b) e 300 cm (c), na área de estudo. 
Segundo Costa (2002), o nitrato é um sal bastante solúvel, característico da contaminação antiga por matéria orgânica, presente em grande quantidade em lixiviados de aterros sanitários. Os nitratos resultam da degradação microbiana de substâncias orgânicas nitrogenadas, como proteínas, e íons de $\mathrm{NH}_{3}{ }^{-}$, as quais são então biologicamente oxidadas para nitritos e nitratos num processo de duas etapas (ALMEIDA et al., 2005).

Segundo Edwards et al. (1972) alguns íons, quando disponibilizados na solução do solo, são rapidamente deslocados no perfil, como é o caso do nitrogênio que, na forma de íons de nitrato, é altamente solúvel em água e apresenta grande mobilidade no solo. O nitrato, por ser um ânion, não é retido em solos cuja predominância de cargas seja negativa apresentando, por isso, grande potencial de lixiviação, o que pode causar sérios problemas de poluição às águas subterrâneas. Mariotti (1998) ainda afirmou que o $\mathrm{NO}_{3}{ }^{-}$, por ser um ânion, não é retido pelos 66 colóides argilosos ou orgânicos do solo, negativamente carregados, o que permite a avaliação do avanço da solução contaminada através do meio poroso. Isso justifica o fato de a maioria dos pontos $(2,5,67$, 8, 9 e 10) apresentarem os maiores valores encontrados nas análises em profundidades iguais ou superiores a $1 \mathrm{~m}$, inclusive estando a maior concentração encontrada em todas as análises no ponto 8 a uma profundidade de $1 \mathrm{~m}$.

Em um estudo realizado por Oliveira et al (2001) onde foi avaliada a lixiviação de nitrato em um Latossolo Amarelo Distrófico, que era submetido a cargas de lodo de esgoto, os autores concluíram que as estimativas da lixiviação de $\mathrm{NO}_{3}{ }^{-}$nas camadas de solo de 0 a $0,9 \mathrm{~m}$ apresentaram grandes perdas deste ânion para todas as camadas do solo. Evidenciaram ainda que existe uma estreita relação entre as movimentações de água no solo e a lixiviação do nitrato.

Para Costa (1999) o lançamento indiscriminado e de compostos nitrogenados oriundos de aterros ou águas residuárias, causa impactos ao meio ambiente e a saúde humana como a doença de origem hídrica como o metahemoglobinemia, ou síndrome do bebê azul, em razão da elevada concentração de nitrato.

Segundo Diniz (2010) o nitrato, por ser um ânion, não é retido em solos cuja predominância de cargas seja negativa apresentando, por isso, grande potencial de lixiviação, o que pode causar sérios problemas de poluição às águas subterrâneas.

Altas concentrações de nitrato na água são problemáticas para potabilidade pois, no corpo humano, o nitrato tem o poder de reduzir a capacidade de transporte de oxigênio do corpo (Owens, 1994).

\subsection{Nitrito $\left(\mathrm{NO}_{2}^{-}\right)$}

Os mecanismos biológicos mais importantes de degradação dos resíduos sólidos urbanos (RSU) em aterro sanitário são a degradação aeróbia por microrganismos na presença de oxigênio molecular ou excepcionalmente incorporado a elementos minerais como nitrato e a degradação anaeróbia por microrganismos na ausência de oxigênio (CASTILHO JÚNIOR, 2003).

Em estudo realizado com diferentes fontes e intervalos de aplicação de nitrogênio, Cardoso Neto et al. (2006) encontraram que o maior acúmulo de $\mathrm{NO}_{2}{ }^{-}$ocorreu no intervalo de profundidade entre 30 e $40 \mathrm{~cm}$, apesar da análise de regressão não ter mostrado significância desse acúmulo ao longo do perfil do solo.

A Figura 8 ilustra a variação da concentração de $\mathrm{NO}_{2}{ }^{-}$nas profundidades de 0 (a), 50 (b), 100 (c) e $150 \mathrm{~cm}(\mathrm{~d})$, onde a maior concentração $\left(0,02172 \mathrm{mg} \mathrm{g}^{-1}\right.$ de solo) foi observada no P2 a $150 \mathrm{~cm}$, e a menor $\left(0,0001 \mathrm{mg} \mathrm{g}^{-1}\right.$ de solo) foi observada no P3 a $50 \mathrm{~cm}$ e no P6 a $150 \mathrm{~cm}$. Na profundidade de $0 \mathrm{~cm}$, o maior valor esteve presente no P4 na concentração de $0,008 \mathrm{mg} \mathrm{g}^{-1} \mathrm{de}$ solo, e o menor foi observado no P5 na concentração de $0,003 \mathrm{mg} \mathrm{g}^{-1}$ de solo. A $50 \mathrm{~cm}$ de profundidade, o maior valor foi obtido no P2 $\left(0,005 \mathrm{mg} \mathrm{g}^{-1}\right.$ de solo) e o menor no P3 (0,0001 mg g $\mathrm{g}^{-1}$ de solo). A $100 \mathrm{~cm}$, a maior concentração observada foi de $0,004 \mathrm{mg} \mathrm{g}^{-1}$ de solo (P2), e a menor foi de 0,0002 
$\mathrm{mg} \mathrm{g}^{-1}$ de solo (P6). Na profundidade de $150 \mathrm{~cm}$, o P2 apresentou a maior concentração $(0,02172$ $\mathrm{mg} \mathrm{g}^{-1}$ de solo), e a menor foi observada no P6 $\left(0,0001 \mathrm{mg} \mathrm{g}^{-1}\right.$ de solo).

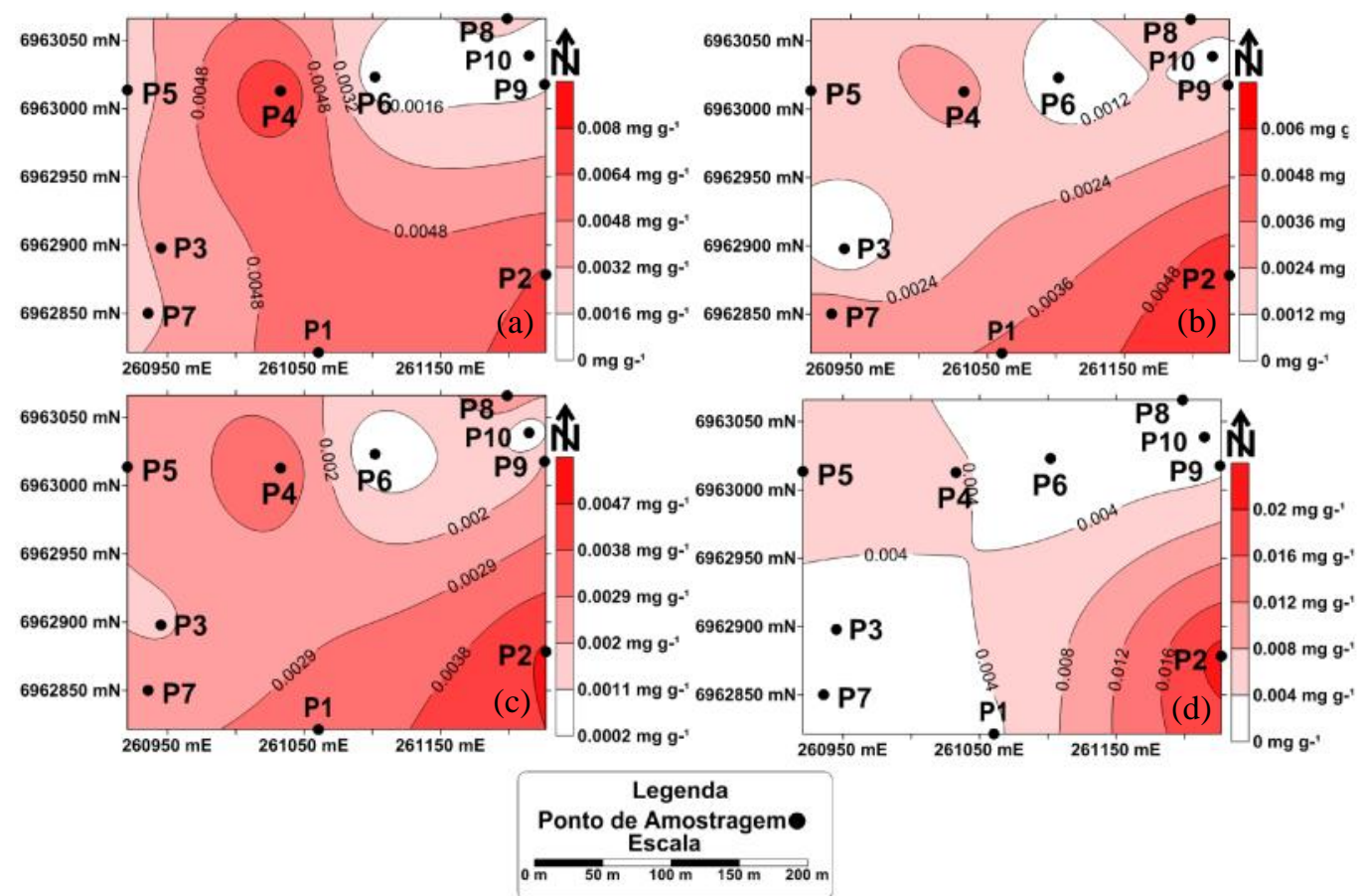

Figura 8. Concentração de nitrito nas profundidades de 0 (a), 50 (b), 100 (c) e $150 \mathrm{~cm}$ (d), na área de estudo.

A Figura 9 ilustra a variação da concentração de $\mathrm{NH}_{3}{ }^{-}$nas profundidades de 200 (a), 250 (b) e $300 \mathrm{~cm}$ (c). A maior concentração foi observada no P2 (0,020 $\mathrm{mg} \mathrm{g}^{-1}$ de solo), e a menor (<L.D.) foi encontrada no P1, ambas a $200 \mathrm{~cm}$. Na profundidade de $250 \mathrm{~cm}$, o maior valor foi obtido no P1 $\left(0,018 \mathrm{mg} \mathrm{g}^{-1}\right.$ de solo) e o menor no P6 (0,0002 $\mathrm{mg} \mathrm{g}^{-1}$ de solo). Na profundidade de $300 \mathrm{~cm}$ o P1 apresentou a maior concentração $\left(0,017 \mathrm{mg} \mathrm{g}^{-1} \mathrm{de}\right.$ solo), enquanto a menor foi observada no P6 $\left(0,0002 \mathrm{mg} \mathrm{g}^{-1}\right.$ de solo). Para uma média de todas as análises, este elemento apresentou concentração de $0,004 \pm 0,004 \mathrm{mg} \cdot \mathrm{g}^{-1}$.

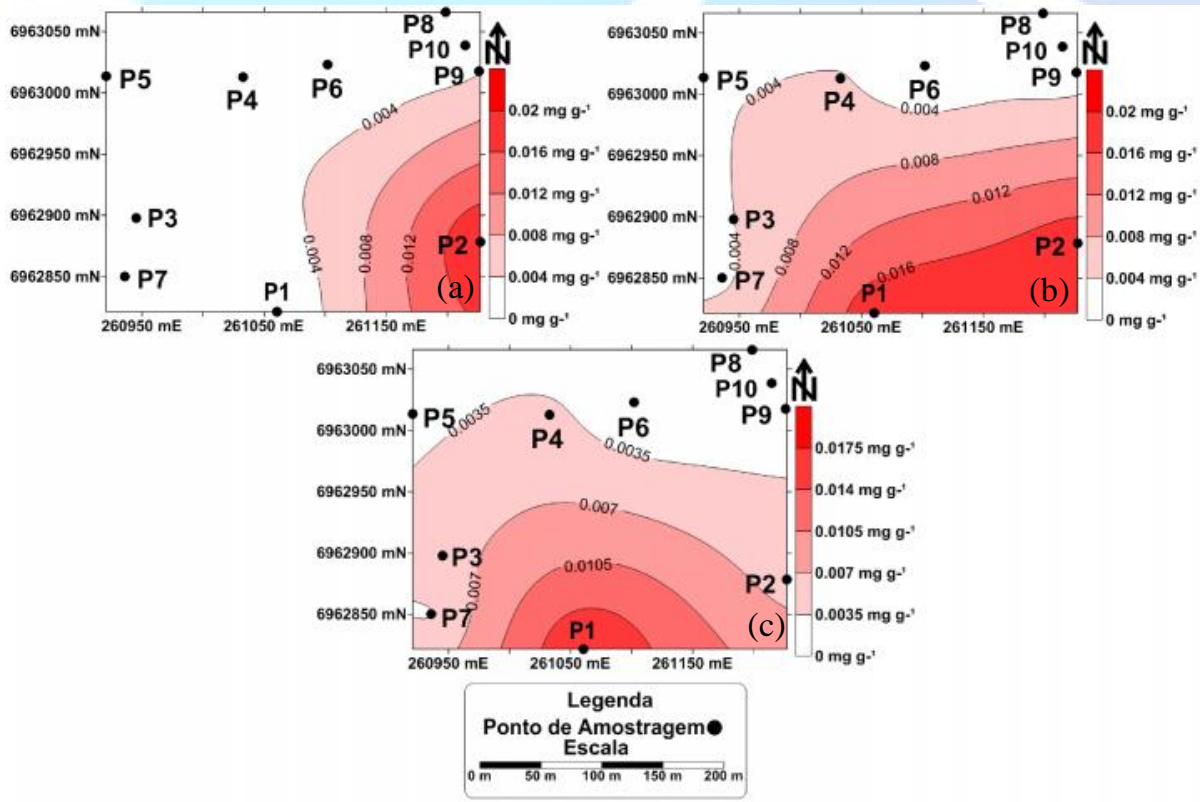

Figura 9. Concentração de nitrito nas profundidades de 200 (a), 250 (b) e $300 \mathrm{~cm}$ (c), na área de estudo. 
Após análise na área de estudo do comportamento do Nitrito nos 10 pontos de amostragem, foi possível identificar que o mesmo apresentou concentrações variáveis nas profundidades de 0 a 3 m. Como por exemplo, os pontos 1 e 2 apresentaram concentrações semelhantes, porém em diferentes profundidades. O mesmo fato foi identificado entre os pontos 3 e 4, além dos demais presentes, sendo que a maior concentração ocorreu no ponto 1, na maior cota topográfica na profundidade de $0,5 \mathrm{~m}$. No restante da área, as maiores concentrações ocorreram nas profundidades variando de 1,5 a $3 \mathrm{~m}$.

Os valores de nitrito no solo foram considerados baixos em todos os pontos analisados. Segundo Hassett e Banwart (1992), em condições favoráveis à nitrificação, a oxidação do nitrito a nitrato é rápida, podendo ser esse o motivo pelo qual o nitrito ocorreu em quantidades baixas no solo analisado.

Em solo alcalino no processo de nitrificação a atividade da bactéria pode haver uma acumulação de nitrito no solo. Durante a oxidação do amônio (NH4) a nitritos e nitratos (nitrificação) por bactérias do gênero Nitrosomonas (nitratos) a ocorrência de alagamento, aumento da alcalinidade, ascenção dos carbonatos ou outro fator poderia alterar o desenvolvimento das populações dessas bactérias. Isso condicionaria maior produção de nitritos tanto pela não oxidação destes como pela redução dos nitratos existentes. Ambas as bactérias são essencialmente aeróbicas (CUNHA, 1985).

\subsection{Correlação estatística entre os parâmetros analisados}

A Tabela 1 ilustra a correlação estatística entre os parâmetros analisados. Como pode ser observado, o parâmetro altitude apresentou correlação significativa com o nitrato $(0,41)$. Os demais parâmetros não apresentaram correlação significativa entre si.

Tabela 1 - Correlação estatística entre profundidade, altitude, amônia, nitrito e nitrato.

\begin{tabular}{cccccc}
\hline & Profundidade & Altitude & Amônia & Nitrito & Nitrato \\
\hline Profundidade & 1,00 & & & \\
Altitude & $-0,00$ & 1,00 & & \\
Amônia & $-0,23$ & $-0,11$ & 1,00 & \\
Nitrito & 0,18 & $0,41^{*}$ & $-0,15$ & 1,00 & \\
Nitrato & 0,12 & $-0,22$ & $-0,02$ & 0,00 & 1,00 \\
\hline
\end{tabular}

*Apresenta correlação significativa $(\mathrm{p}<0,05 / \mathrm{N}=70)$ entre os parâmetros.

\section{CONCLUSÕES}

Os maiores teores dos compostos nitrogenados avaliados nos pontos do aterro sanitário, nem sempre se encontram nos locais de cotas mais baixas do terreno, que geralmente são considerados mais vulneráveis ao acúmulo. Por o aterro ser uma área que recebe diariamente uma elevada carga orgânica, o esperado seria que as maiores concentrações dos componentes nitrogenados estivessem em nível superficial ou em profundidades próximas da superfície. Isso não foi comprovado em todos os casos, revelando que mesmo o solo do aterro sendo bastante argiloso, não está compactado e/ou impermeabilizado o suficiente para evitar a lixiviação dos componentes nitrogenados, assim permitindo que os mesmos cheguem até camadas mais profundas do solo. 


\section{REFERÊNCIAS}

ALMEIDA P.S. Armazenamento de Lixo Urbano em Lixões e Aterros Sanitários:

Contaminação do Solo, Proliferação de Macro e Micro Vetores e Contaminação do Lençol Freático. 2009. Disponível em: < http://social.stoa.usp.br/wagnerk/trabalho-1-de-smc-professorpauloalmeida .pdf? view=true $>$ Acesso: Dezembro de 2012.

ARAÚJO A.L.C.; FIGUEIREDO F.G.; VALE M.B. do; FONSECA, A.L. da; VASCONCELOS N.S. Avaliação Preliminar da Concentração de Nitratos nas Águas Subterrâneas de Abastecimento na Região Urbana de Parnamirim-RN. In: XXIII Congresso Brasileiro de Engenharia Sanitária e Ambiental, 23, 2005, Campo Grande - MS. Anais... XXIII CBESA, 2005.

CAMPOS D.C.; LEITE V.D.; LOPES W.S.; RAMOS P.C. de A. Stripping de amônia de lixiviado de aterro sanitário em reatores de fluxo pistonado. Revista Tecno-Lógica, Santa Cruz do Sul-RS, v.14, n. 2, p.52-60, 2010.

CARDOZO NETO, F.; GUERRA, H.O.C.; CHAVES, L.H.G. Nitrogênio residual num solo adubado com diferentes fontes e intervalos de aplicação de nitrogênio. Revista Caatinga, MossoróRN, v.19, n.2, p.161-168, 2006.

CASTILHOS JÚNIOR, A.B. de. Resíduos sólidos urbanos: aterro sustentável para municípios de pequeno porte. Rio de Janeiro: ABES, RiMa, 2003. 288p.

COSTA, N.M. da.; MARTINEZ, M.A.; MATOS, A.T. de.; RAMOS, V.B.N. Mobilidade de nitrato em colunas de solo sob condições de escoamento não permanente. Revista Brasileira de Engenharia Agrícola e Ambiental, Campina Grande-PB, v.3, n.2, p.190-194, 1999.

COSTA, P.O.S. Avaliação em laboratório, do transporte de contaminantes no solo do aterro sanitário de Sauípe/BA. 2002, 188f. Dissertação (Mestrado em Engenharia Civil), Departamento de Engenharia Civil. Pontifícia Universidade Católica do Rio de Janeiro, Rio de Janeiro. 2002.

CUNHA, N.G. Clorose em forrageiras em solos calcimórficos na sub-região do Abobral. EMBRAPA: Corumbá, 1985. 52p.

DINIZ, D.T.L. Remoção de Nitrogênio Amoniacal de Lixiviado de Aterro de Resíduos Sólidos por Precipitação Química com Formação de Estruvita. 2010, 111f. Dissertação (Mestrado em Tecnologia Ambiental e Recurso Hídricos). Departamento de Engenharia Civil e Ambiental. Universidade de Brasília, Brasília, 2010.

EDWARDS, D.M.; FISCHBACH, P.E.; YOUNG, L.L. Movement of nitrate under irrigated agriculture. Transactions of the ASAE. St. Joseph. v.15, n.1, p.73-5, 1972.

GOLDEN SOFTWARE, Inc. Surfer 8.0: Contouring and 3D Surface Mapping for Scientists and Engineers. User's Guide, 2004.

HE, S.; ZHANG, Y.; YANG, M.; DU, W.; HARADA, H. Repeated use of MAP decomposition residues for the removal of high ammonium concentration from landfill leachate. Chemosphere, Oxford, v.66, p.2233-2238, 2007. 
HASSET, J.J.; BANWART, W.L. Soils and their environment. New Jersey: Englewood Cliffs, 1992. 424p.

INSTITUTO BRASILEIRO DE GEOGRAFIA E ESTATÍSTICA - IBGE. Contagem da população. Disponível em: <http://www.ibge.gov.br>. Acesso: Dezembro de 2012.

KEMERICH, P.D.C.; BORBA, W.F.; SILVA, R.F.; BARROS, G.; GERHARDT, A.E.; FLORES, C.E.B. Valores anômalos de metais pesados em solo de cemitério. Revista Ambiente \& Água, Taubaté - SP, v.7, n.1, p. 140-156, 2012.

LANDIM, P. M. B.; STURARO, J. R. Krigagem indicativa aplicada à elaboração de mapas probabilísticos de riscos. Rio Claro: DGA, IGCE, UNESP, 2002. 250p.

MARIOTTI, A. Nitrate: un poluant de longue durée. Pour la Science: Le Monde, 1998. 102p.

MARTINEZ R. R. Estudo Teórico e Experimental de Agregados Iônicos (NH3)nNHm \pm Dessorvidos de Amônia Sólida Bombardeada por Íons de $65 \mathrm{MeV}$. Tese de Doutorado em Física. Departamento de Física. Pontifica Universidade Católica do Rio de Janeiro, Rio de Janeiro, 2007, 120f.

MEINERZ, C. C.; KLEINB, J. C.; DIMBARRE, S. C.; MONDARDOD, D.; BELLONE, P. P.; SANTOS, L. B. ; SCHERER, F. Estudo de Caso para Recuperação Paisagística do Aterro Sanitário de Toledo - PR. In: $2^{\text {nd }}$ International Workshop: Advances In Cleaner Production. São Paulo: USP.

MELO, M. C. de. Uma Análise de Recalques Associada a Biodegradação no Aterro de Resíduos Sólidos da Muribeca. Dissertação de Mestrado em Engenharia Civil. Departamento de Engenharia Civil. Universidade Federal de Pernambuco, Recife, $126 f$.

MOURA, D. A. G. Remoção de Amônia por Arraste com Ar de Lixiviados de Aterros Sanitários. Dissertação de Mestrado em Ciências. Departamento de Química, Escola de Química. Universidade Federal do Rio de Janeiro, Rio de Janeiro, 2008, 131f.

OLIVEIRA, F. C.; MATIAZZO, M. E.; MARCIANO, C. R.; MORAES, S. A. Lixiviação de nitrato em um latossolo amarelo distrófico tratado com lodo de esgoto e cultivado com cana-de-açúcar.

Revista Scientia Agrícola Piracicaba-SP, v.58, n.1, p. 171-180, 2001.

OWENS, L. B. Impacts of soil $\mathrm{N}$ management on the quality of surface and subsurface water. In: LAL, R.; STEWART, B.A. ed. Soil processes and water quality. Lewis Publication, p. 137-162. 1994.

RODRIGUES, M. R. M. Tratabilidade do Lixiviado Efluente da Lagoa Facultativa do Aterro de Curitiba por Lodo Ativado. Curitiba: UFPR. Dissertação de Mestrado em Engenharia de Recursos Hídricos e Ambiental. 142 f.

SANTANA, O. A.; ENCINAS, J. I. Composição Química do Solo e da Água Subterrânea em Áreas Adjacentes a Aterros Sanitários. Revista Brasileira de Ciências Agrárias, Recife - PE, v.4, n.3, p.318-328, 2009. 
SANTANA, O. A.; ENCINAS, J. M. I. Modelo espacial de contaminação do solo e do lençol freático do aterro do Jockey Club para o parque nacional de Brasília, Brasília - DF. In: Simpósio Brasileiro de Cartografia Geotécnica e Geoambiental, 20, 2009, São Carlos. Anais... SBCGG, 2009.

TEDESCO, M. J.; VOLKWEISS, S. J.; BOHEN, H. Análises de solo, plantas e outros materiais. Porto Alegre: UFRGS, 1985. 188p. 